\title{
Management of residual and recurrent caries in
}

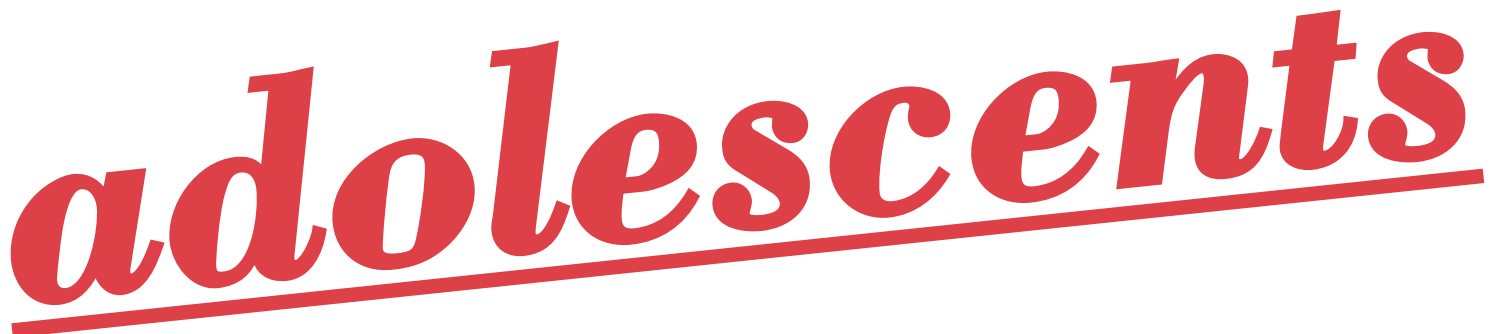

\section{By dental therapist and hygienist Carolyn Renton*}

\section{Dental caries}

Dental caries is a reversible progressive disease of the dental tissues initiated by the action of bacteria on fermentable carbohydrates in the biofilm on tooth surfaces. ${ }^{1}$
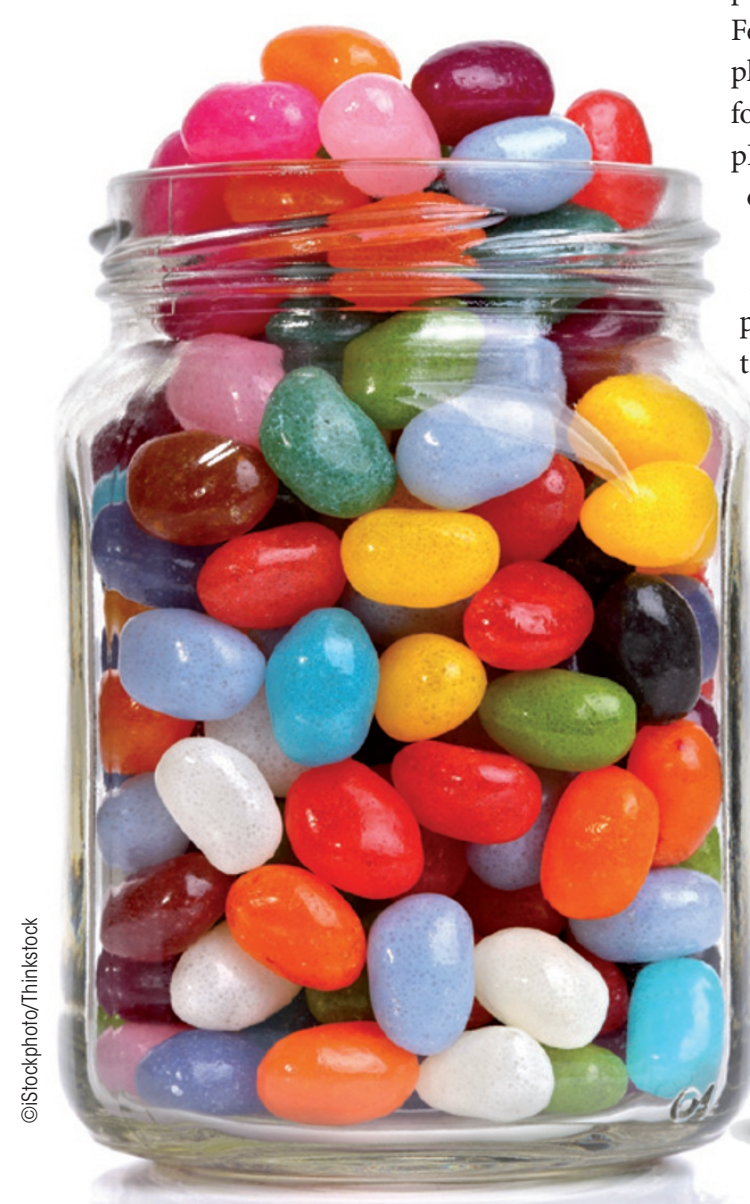

Streptococcus mutans and lactobacilli quickly produce acid from fermentable carbohydrates adhering to the tooth surface because of their ability to synthesise sticky extracellular polysaccharides from dietary sugar.

Fermentable carbohydrates and cariogenic plaque need to be present on a tooth surface for acid to form. 'Stephan's curve' illustrates $\mathrm{pH}$ changes and shows that the gradual return of $\mathrm{pH}$ will result in the acid diffusing out of this plaque. This is because the saliva has a 'buffering ability' where calcium and phosphate fluoride enters by facilitated transport over membranes over the salivary gland tissue. Many theories have been considered into the aetiology of caries but to date it is the acidogenic theory described by Miller in the 1800s that has been proved the most likely cause. Epidemiological studies such as Tristan da Cunha in the 1930s, Hopewood House in 1942, and the Vipeholm study in 1945 all demonstrate that when refined carbohydrates are introduced into the diet at an overwhelming rate, dental caries inevitably ensues.

\section{Residual caries}

Residual caries is demineralised tissue left behind when a filling is placed ${ }^{2}$ and it can be active or arrested. It is difficult to determine what the lesion is as there is a continuum of transient changes that can either: rapidly progress, slowly progress, or not progress at all: at this point the arrested lesion becomes chronically remineralised. If the lesion is not active no treatment is required, however, when it is active treatment is required to further prevent demineralisation.

\section{Recurrent caries}

Recurrent caries is a primary caries lesion next to a pre-existing filling. It usually forms cervically and interproximally due to plaque stagnation. ${ }^{3}$ Recurrent caries is potentially serious as once dentine is reached it can spread rapidly. ${ }^{4}$ When limited to the immediate area of margin the caries can be removed and a 'repair' restoration can be placed.

\section{Residual and recurrent caries determination}

There are many methods of determining residual and recurrent caries:

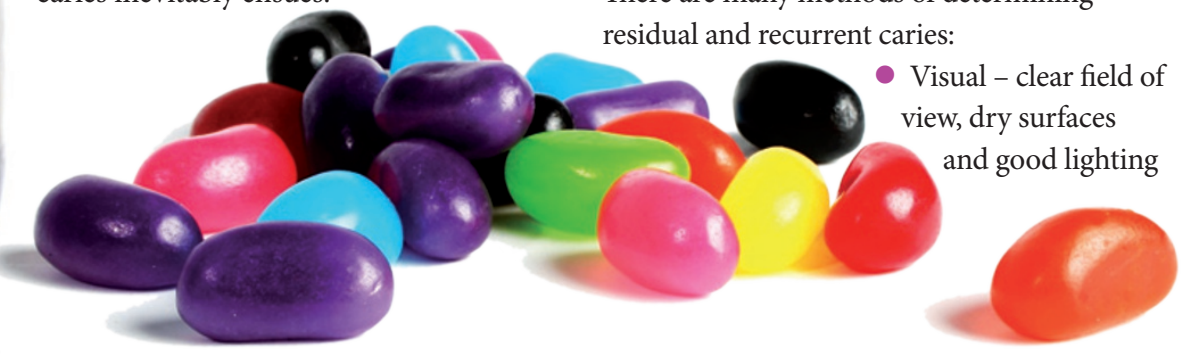


- FOTI - Fibre Optic Trans-Illumination Radiography (pros: shows interproximal lesions and depth of lesions; cons: does not distinguish between cavitated and noncavitated lesions)

- Tooth separation (pros: suitable for teenagers - well tolerated and accepted; cons: time consuming - needs a minimum of two visits).

Residual and recurrent caries can easily be confused with marginal leakage. It is recommended that intervention is postponed and polishing and smoothing of the restoration junction takes place, with regular monitoring, prior to intervention. ${ }^{5}$ Amalgam fillings may display ditching and discolouration but this is neither synonymous with, nor indicative of, decay especially on the occlusal surface. ${ }^{3}$ Composites similarly may have stain and colour change but this does not reliably predict active decay. When making decisions in operative dentistry, it is suggested to consider why new lesions have occurred, ${ }^{6}$ as new lesions suggest the patient is not complying with preventative regimes. It is crucial to find the origin of the aetiology of recurrent caries to prevent an ongoing cycle which may be detrimental to the teenage patient. The first step is to explore the patient's current habits.

\section{Factors to investigate \\ 1. Medical history}

- Sugared medicines - teenagers are more likely to prefer medicine to tablets

- Saliva inhibiting disease - Sjögren's syndrome, radiotherapy, xerostomia, hyposalivation

- Substance abuse - alcohol, methadone, smoking

- Chronic illness - mental illness leading to poor dexterity

- Bulimia

\section{Dental history}

- High caries rate

- Heavily restored dentition

- Phobias, anxieties

\section{Oral hygiene}

- Tooth brushing frequency

- Interdental cleaning habits

- Fluoride toothpaste or mouthwash usage

- Rinse or spit habits

- Orthodontic appliances

\section{Social and demographic factors \\ - Lifestyle changes \\ - Socio-economic group.}

\section{'It is essential to remember that caries of any kind can become arrested at any age or stage.}

When all of these considerations have been explored the clinician is in an optimum position to facilitate a teenager in managing the current situation and preventing further episodes. It is essential to remember that dental caries of any kind: new, residual or recurrent can become arrested at any age or stage of destruction, so passive management is the essential initial step. Prevention is best performed with the patient in a systematic way.

\section{Stages in management 1. Patient motivation \\ - Communication \\ - Education}

\section{Diet}

Dietary analysis - as advised by Moynihan 7 (adapted for Vital in summer $2007 \mathrm{http}: / /$ www.nature.com/vital/journal/v4/n2/full/ vital597.html)

- Dietary advice: including modification of sugar frequency, Department of Health ${ }^{8}$

- Sugar-free alternatives advice

- Cheese

- Xylitol sugar-free gum after meals considered controversial by Maguire and Rugg-Gunn, ${ }^{9}$ but recommended by Burt ${ }^{10}$

\section{Oral hygiene advice}

- Effective removal of plaque; suitable toothbrush

- Bleeding caused by brushing; understanding inflammation resolves with good $\mathrm{OHI}$

- Quality over quantity

\section{Interdental cleaning}

- Efficient technique - wide range of aids available

- Understanding the cause of bleeding with brushing

\section{Fluoride}

- Community: $\mathrm{H}_{2} \mathrm{O}$ (1 ppm)

Toothpaste 1-5000 ppm (depending on caries rate $)^{11}$

- Mouthwash $0.05 \% 0.1 \% \mathrm{NaF}$ daily or $0.2 \%$ weekly $^{11}$

- Topical - gels/varnish $2.25 \%$

\section{Regular professional monitoring}

- Plaque disclosing

- Plaque removal

Fluoride varnish $2 \%$
7. Treatment

- Fissure sealants

- Glass ionomer restorations.

\section{Conclusion}

Dental caries occurs when fermentable carbohydrates and cariogenic plaque are left on a tooth surface for a period of time, on a frequent basis. It can be new, recurrent or residual and it can be arrested at any stage. There are many stages and factors to take into consideration before clinical intervention and the dental care professional (DCP) can be invaluable in educating, advising and monitoring the development and halt of dental caries.

1. Banerjee A, Watson T J. Pickard's manual of operative of dentistry, 9th ed. Oxford University Press, 2012.

2. Fejerskov O, Kidd E. Dental caries, the disease and its clinical management, 2nd ed. Oxford: Blackwell Munksgaard, 2003.

3. Kidd E. Essentials of dental caries, the disease and its management, 3rd ed. Oxford University Press, 2005.

4. Jacobsen P. Restorative dentistry, an integrated approach, 2nd ed. Oxford: Wiley Blackwell, 2008.

5. Walmsley A D, Walsh T F, Lumley P J et al. Restorative dentistry, 2nd ed. London: Churchill Livingstone Elsevier, 2007.

6. Brunton P A. Decision-making in operative dentistry. London: Quintessence Publishing Co. Ltd, 2002.

7. Moynihan P. Dietary advice in dental practice. Br Dent J 2001; 193: 563-568.

8. Department of Health. Delivering better oral health: an evidence based toolkit for prevention, 2nd ed. British Association for the Study of Community Dentistry, 2009.

9. Maguire A, Rugg-Gunn A J. Xylitol and caries prevention - is it a magic bullet? Br Dent J 2003; 194: 429-436.

10. Burt B A. The use of sorbitol and xylitol sweetened chewing gum in caries control. J Am Dent Assoc 2006; 137: 190-196.

11. Marinho V C C, Higgins J P T, Logan S, Sheiham A. Fluoride mouthrinses for preventing dental caries in children and adolescents. The Cochrane Collaboration, Intervention review. Wiley Publishing, 2009.

${ }^{*}$ Carolyn Renton qualified as dental therapist and hygienist in 2006 and has nearly 20 years' experience in the dental industry. She works in two dental practices in Leicester and Nottingham and is currently studying for a BSc

in Dental Studies at the University of Central

Lancashire.

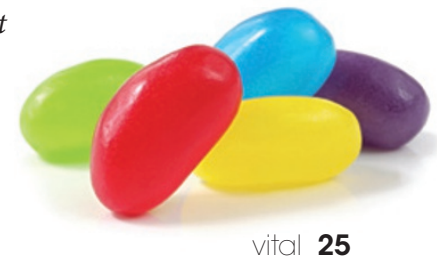

